\title{
Correction to: Dynamic analysis of 1-dof and 2-dof nonlinear energy sink with geometrically nonlinear damping and combined stiffness
}

\author{
Yunfa Zhang • Xianren Kong • Chengfei Yue • \\ Huai Xiong
}

Published online: 4 August 2021

(C) Springer Nature B.V. 2021

\section{Correction to: Nonlinear Dyn https://doi.org/10.1007/s11071-021-06615-9}

The article has been updated. The original article has been corrected.
Publisher's Note Springer Nature remains neutral with regard to jurisdictional claims in published maps and institutional affiliations.

The online version of the original article can be found under https://doi.org/10.1007/s11071-021-06615-9.

Y. Zhang $\cdot$ X. Kong $(\varangle)$

Research Center of Satellite Technology, Harbin Institute of Technology, Harbin 150080, China

e-mail: kongxr@hit.edu.cn

C. Yue

Institute of Space Science and Applied Technology, Harbin Institute of Technology, Shenzhen 518055, China

H. Xiong

Aerospace System Engineering Shanghai, Shanghai 201109, China 